\title{
Focal low-dose-rate prostate brachytherapy for low- and intermediate-risk prostate cancer
}

\author{
Hiroaki Kunogi, MD, PhD!', Yoshiaki Wakumoto, MD, PhD², Terufumi Kawamoto, MD, PhD', Masaki Oshima, MD!, \\ Shigeo Horie, MD, PhD², Keisuke Sasai, MD, PhD' \\ 'Department of Radiation Oncology, Juntendo University, Tokyo, Japan, ${ }^{2}$ Department of Urology, Juntendo University, Tokyo, Japan
}

\begin{abstract}
Purpose: To prospectively investigate the efficacy and feasibility of focal low-dose-rate (LDR) prostate brachytherapy for low- and intermediate-risk prostate cancer.

Material and methods: Between October 2014 and May 2019, nineteen low- and intermediate-risk prostate cancer patients who presented with abnormality on both diffusion-weighted and T2-weighted magnetic resonance imaging (MRI) underwent focal LDR brachytherapy at our institution. Focal gross tumor volume (F-GTV) was delineated on transrectal ultrasound, based on abnormality seen on fused T2-weighted MRI. F-GTV was expanded by $5 \mathrm{~mm}$, as a safety margin, to create focal clinical target volume (F-CTV). Prescribed dose to F-CTV was 145 Gy. Biochemical recurrence (BCR) was determined using Phoenix criterion (prostate specific antigen nadir $+2 \mathrm{ng} / \mathrm{ml}$ ). Pre- and post-implant dosimetry data were compared using non-parametric Wilcoxon's rank sum test. Treatment-related toxicities were evaluated using common terminology criteria for adverse events.

Results: Mean F-CTV $D_{90 \%}$ was significantly lower in the post-implant evaluation than in intraoperative planning $(p=0.004)$. On post-implant dosimetry, the mean $\mathrm{D}_{90 \%}$ for F-GTV and mean $\mathrm{V}_{100 \%}$ for the entire prostate were $222 \mathrm{~Gy}$ and $35 \%$, respectively. Median follow-up time for all patients was 31 months. BCR occurred in one patient after 23 months. Kaplan-Meier 2-year BCR-free rate was 92.9\% (95\% confidence interval [CI]: 79.4-100\%). No patients had grade 1 or greater gastrointestinal toxicity. Three patients who were taking $\alpha$-blockers to treat benign prostatic hyperplasia (present before brachytherapy), experienced no treatment-related genitourinary toxicities. Two patients suffered from temporary grade 2 urinary frequency. None of the remaining patients experienced grade 2 or higher genitourinary toxicity.

Conclusions: Focal LDR prostate brachytherapy appears acceptable for MRI-based index tumors, with a low cumulative incidence of BCR. Such brachytherapy might offer a feasible minimally invasive therapeutic option for localized prostate cancer.

J Contemp Brachytherapy 2020; 12, 6: 554-561 DOI: https://doi.org/10.5114/jcb.2020.101688
\end{abstract}

Key words: focal therapy, LDR brachytherapy, prostate cancer.

\section{Purpose}

Globally, prostate specific antigen (PSA) screening has resulted in an increase in the diagnosis of low- and intermediate-risk prostate cancer [1]. Radical wholegland therapies provide excellent oncological outcomes for these patients. Low-dose-rate (LDR) whole-gland prostate brachytherapy provides excellent oncological outcomes [2]; however, excessive treatment may influence quality-of-life. Although prostate cancer is mostly a multi-focal disease [3], recent evidence indicates that focal therapy delivered to the index lesion, the largest tumor focus within the prostate, may effectively control disease. Thus, this is a new radical treatment for low- and intermediate-risk prostate cancer $[4,5,6,7,8]$. Several modalities, such as high-intensity focused ultrasound, cryo- therapy, laser ablation, and photodynamic therapy have been developed to facilitate focal therapy [5].

In focal therapy, permanent prostate brachytherapy using ${ }^{125} \mathrm{I}$ can be an effective option for prostate cancer $[6,7]$. It has been reported that focal brachytherapy may reduce acute morbidity, because dose reductions during whole-gland prostate brachytherapy were associated with reduced acute urinary morbidity [9]. Few studies have evaluated focal ${ }^{125}$ I prostate brachytherapy. A characteristic feature of permanent prostate brachytherapy is seed motion, including seed migration, which may lead to a fear of PSA failure due to difficulty with delivering the dose to a small volume. The purpose of this study was to assess the effectiveness of focal LDR brachytherapy using a safety margin to develop an effective treatment option for focal treatment.

\footnotetext{
Address for correspondence: Hiroaki Kunogi, MD, PhD, Department of Radiation Oncology, Juntendo Received: 12.05 .2020 University, 2-1-1, Hongo, Bunkyo-ku, Tokyo, 113-8421, Japan, phone: +81-3-3813-3111, fax: +81-3-3816-0958, Accepted: 09.09.2020 


\section{Material and methods}

\section{Patient eligibility criteria for focal brachytherapy}

The eligibility criteria for focal implantation included pre-treatment Gleason score $\leq 7$, PSA level $<15 \mathrm{ng} / \mathrm{ml}$, clinical $\mathrm{T}$ stage $\leq \mathrm{T} 2 \mathrm{c}$, and no prior radiotherapy to the pelvis. Diagnosis of the focus area (clinically significant cancer) by an abnormality on both diffusion-weighted and T2-weighted images (DWI and T2WI, respectively) were obtained by magnetic resonance imaging (MRI), which coincided with positive biopsies (either a systematic bilateral prostate transperineal biopsy or a transrectal ultrasound (TRUS)-guided biopsy, based on cognitive fusion or MRI-TRUS fusion employing the BioJet (GeoScan, Lakewood Ranch, FL, USA)), with no lymph node or distant metastases on computed tomography (CT) or bone scan. In principle, 16-core bilateral prostate biopsies were obtained with the patient under general anesthesia, including 8 from the peripheral zone, 4 from the transitional zone, and 4 from the anterior horn. No tumor-related inclusion/exclusion criteria (e.g., tumor location, diameter, or proximity to urethra/rectum) were established. The study was registered in the University Hospital Medical Information Network Clinical Trials Registry (UMIN, No. 003992). Moreover, this study was approved by the ethics committee of our institution (approval No. 13-173). Written informed consent for focal brachytherapy was obtained from each participant prior to seed implantation.

\section{Procedure for focal brachytherapy}

Brachytherapy was performed under general anesthesia. Variseed version 8.0 software (Varian Medical Systems Inc., Palo Alto, CA, USA) was used for treatment planning. Prostate and surrounding normal tissues, with a thickness of $1 \mathrm{~mm}$ were imaged using TRUS, and the entire prostate and rectum were delineated. The urethra was contoured from the prostatic base to the apex using the surface of inserted catheter. To delineate the clinically significant cancer that represented the focus area based on the T2WI abnormality, we performed registration by matching five selected positions: three on the prostatic urethra (the edge on the bladder side, urethral center at the mid-prostate, and edge on the penile bulb side) and two on the right and left peripheral edges at the mid-prostate. The least squares method was used when fusing TRUS and T2WI in the Variseed 8.0 software. After fusion, the focal gross tumor volume (F-GTV) was created from the fused T2-weighted low signal abnormality area and then expanded by $5 \mathrm{~mm}$ to create the focal clinical target volume (F-CTV) to compensate for uncertainties in image registration and treatment delivery, such as movement. The F-CTV contour was restricted either within the prostatic capsule or outside of organs at risk (OARs), such as the urethra, rectum, and bladder. The dose prescribed to the F-CTV during intraoperative planning was $145 \mathrm{~Gy}$.

The planning goal was the following dosimetric constraints: percentages of the entire F-CTV and F-GTV covered by $100 \%$ of the prescription dose $\left(\mathrm{V}_{100 \%}\right)$ of $\geq 90 \%$ and $\geq 98 \%$ of their corresponding structure volumes, respectively. Planning criteria for the OARs were based on the following ESTRO/EAU/EORTC recommendations for whole prostate brachytherapy: the minimum dose received by the maximum irradiated $2 \mathrm{cc}$ of the rectum $\left(R_{2 c c}\right)$ was less than the reference prescription dose, and the minimum dose received by $10 \%$ of the prostatic urethral volume $\left(\mathrm{UD}_{10 \%}\right)$ was less than $150 \%$ of the reference prescription dose [10]. We attempted to deliver the lowest doses reasonably possible to the urethra, rectum, and entire prostate. Sources were evenly implanted on the peripheral edge and central part of the F-CTV under TRUS guidance. A higher dose was delivered to the center of F-GTV, as an increased dose was likely to be required considering the greater number of tumor cells present; thereby, creating a correlation between the total dose and tumor burden.

\section{Post-implant dose evaluation}

Four weeks after seed implantation, post-implant CT and MRI data were acquired for dosimetric analysis. We used advanced MRI-to-CT fusion techniques [11] to mitigate MRI-CT registration error via a two-step fusion of CT scans and T2WIs using fat-suppressed T1-weighted imaging in Variseed 8.0. CT scanning was performed with 1-mm spacing in the supine position, with urinary catheter $(8 \mathrm{Fr}$ ) in place. Two MRI sequences were obtained: fat-suppressed T1-weighted imaging and T2WI with 3-mm spacing. During the fusion steps, the least squares method was used with 12 geometric centers of the seed distribution [11]. Two seed centers were defined on either side (right and left lobes) at the base, middle, and apex of the prostate ( 12 seed centers total). When a sector lacked a seed due to focal seed implantation, a seed center was randomly selected from other sectors. Finally, the images obtained from the advanced T2WI-to-CT fusion technique were fused with the pre-treatment T2WI using the least squares method by matching selected urethral anatomical positions (the base, mid, and apex of prostatic urethra) and each peripheral edge of the mid-prostate on each T2WI (post-implant and pre-treatment). This fused pre-treatment T2WI was used for contouring the postimplant F-GTV volume.

Identification of all implanted seeds was accomplished on the CT images in Variseed 8.0. The entire prostate was contoured on the fused post-implant T2WI. The rectum and bladder were delineated on the $\mathrm{CT}$ images. The urethra was contoured from the prostatic base to the apex using the surface of inserted catheter evident on CT images. The post-implant F-GTV was delineated on fused pre-treatment T2WI. The F-GTV was expanded by $5 \mathrm{~mm}$ to create the post-implant F-CTV (F-GTV plus clinically insignificant disease) in accordance with Groenendaal et al. [12]. As before, the post-implant F-CTV contour was restricted either within the prostatic capsule or outside of the OARs.

The metrics used were the prostate $\mathrm{V}_{100 \%}$, minimum doses delivered to $50 \%$ and $90 \%$ of the entire prostate ( $\mathrm{D}_{50 \%}$ and $\mathrm{D}_{90 \%}$, respectively), minimum doses delivered to $90 \%$ and $100 \%$ of the F-GTV (F-GTV $D_{90 \%}$ and $D_{100 \%}$, respectively), F-CTV $\mathrm{D}_{90 \%}$, minimum doses delivered to 
$10 \%$ and $30 \%$ of the urethral volume $\left(\mathrm{UD}_{10 \%}\right.$ and $\mathrm{UD}_{30} \%$, respectively), and $\mathrm{RD}_{2 \mathrm{cc}}$

\section{Comparison between pre-implant planning dosimetry and post-implant dosimetry}

We compared each of the following metrics between pre- and post-implant dosimetry: F-GTV $\mathrm{D}_{90 \%}$ and $\mathrm{D}_{100 \%}$ F-CTV $\mathrm{D}_{90 \%}, \mathrm{UD}_{10 \%}, \mathrm{UD}_{30 \%}$, and $\mathrm{RD}_{2 \mathrm{cc}}$. The pre-planning F-CTV was the F-GTV plus a 5-mm margin of uncertainty, and the post-implant dosimetry F-CTV was the F-GTV plus a 5-mm margin including any clinically insignificant disease. Therefore, the pre- and post-implant F-CTVs were not the same; however, comparing these values enabled assessing the difficulty of dose delivery in focal

Table 1. Baseline patients' characteristics Characteristics

\begin{tabular}{|c|c|}
\hline \multicolumn{2}{|l|}{ Age (years) } \\
\hline Mean (SD) & $73(4.8)$ \\
\hline Median (range) & $74(62-79)$ \\
\hline \multicolumn{2}{|l|}{ Initial PSA (ng/ml) } \\
\hline Median (range) & $7.3(4.7-9.8)$ \\
\hline \multicolumn{2}{|l|}{ Prostate volume (cc) } \\
\hline Median (range) & $26(14.6-75.3)$ \\
\hline \multicolumn{2}{|l|}{ Gleason score } \\
\hline $3+3$ & $8(42 \%)$ \\
\hline $3+4$ & $10(53 \%)$ \\
\hline $4+3$ & $1(5 \%)$ \\
\hline \multicolumn{2}{|l|}{ Tumor stage } \\
\hline $\mathrm{T} 1 \mathrm{c}$ & $0(0 \%)$ \\
\hline $\mathrm{T} 2 \mathrm{a}$ & $14(74 \%)$ \\
\hline $\mathrm{T} 2 \mathrm{~b}$ & $4(21 \%)$ \\
\hline $\mathrm{T} 2 \mathrm{C}$ & $1(5 \%)$ \\
\hline \multicolumn{2}{|l|}{ Risk stratification } \\
\hline Low & $5(26 \%)$ \\
\hline Favorable intermediate & $13(68 \%)$ \\
\hline Unfavorable intermediate & $1(5 \%)$ \\
\hline \multicolumn{2}{|l|}{ Neoadjuvant hormonal therapy } \\
\hline Yes & $7(37 \%)$ \\
\hline No & $12(63 \%)$ \\
\hline Total cores, median (range) & $16(10-17)$ \\
\hline Positive cores, median (range) & $2(1-5)$ \\
\hline $\begin{array}{l}\text { Percentage of positive cores, median } \\
\text { (range) }\end{array}$ & $12.5(6.3-33 \%)$ \\
\hline
\end{tabular}

LDR brachytherapy. Indeed, the dose to the post-implant F-CTV was significantly lower than that to intraoperative F-CTV $(p=0.004)$.

\section{Patient follow-up (PSA, MRI, and toxicity)}

Prostate specific antigen measurements were performed at short intervals (every 1-3 months) post-operatively. Biochemical recurrence $(\mathrm{BCR})$ was determined using Phoenix criterion (PSA nadir $+2 \mathrm{ng} / \mathrm{ml}$ ) $[13,14]$. If the PSA level increased to the pre-treatment level, we recommended a $5-\mathrm{mm}$ transperineal template mapping biopsy (TTMB). To evaluate the control of MRI-based significant cancer within the prostate, multiparametric MRI (mpMRI) was performed at between 18 and 36 months after implantation.

Genitourinary (GU) and gastrointestinal (GI) toxicities were evaluated using the common terminology criteria for adverse events, version 4.0 [15]. Toxicity was evaluated at baseline and every 1-2 months post-operatively. Sexual dysfunction is often evaluated after brachytherapy [16]; however, this was impossible in this study because 15 of the 19 patients $(79 \%)$ exhibited severe erectile dysfunction (ED) prior to focal brachytherapy. None requested medication; thus, we could not determine whether ED was refractory to medication.

\section{Statistics}

Differences in the mean value of each dose-volume parameter between intraoperative planning and post-implant evaluation were compared using non-parametric Wilcoxon's rank sum test. Because of the limited sample size, normal distribution was not assumed. Statistical analyses were performed using SPSS, version 18 (SPSS Inc., Chicago, IL, USA). $P$-values less than 0.05 were considered statistically significant.

\section{Results \\ Patient characteristics}

The clinical data of patients followed up for more than 12 months after focal brachytherapy are shown in Table 1. A median of 16 cores was obtained on bilateral prostate biopsy (range, 10-17). Of the 19 patients, $3(16 \%)$ underwent additional TRUS-guided biopsy based on cognitive fusion or MRI-TRUS fusion at the focus area, of whom 2 presented with positive biopsy cores. Between October 2014 and May 2019, the 19 patients underwent transperineal brachytherapy using ${ }^{125} \mathrm{I}$ radioactive seeds (Oncoseed 6711, GE Healthcare Medi-Physics Inc., Arlington Heights, IL, USA; custom-linked STM1251, C.R. Bard, Covington, GA, USA; or TheraStrand Single Load, Theragenics Corporation, Buford, GA, USA) at our institution. In 18 of the 19 patients, the single largest tumor focus was treated; for the remaining patient (with two MRI-evident lesions of the same size), both lesions were treated. To reduce seed motion or migration, we used custom-linked [17] or bioabsorbable polymer-coated [18] seeds for all but one patient. The median PSA nadir after focal brachytherapy was 1.02 (range, $0.23-4.3$ ) ng/ml. Figure 1 shows the abnormality on pre-treatment T2WI and DWI, and a CT 


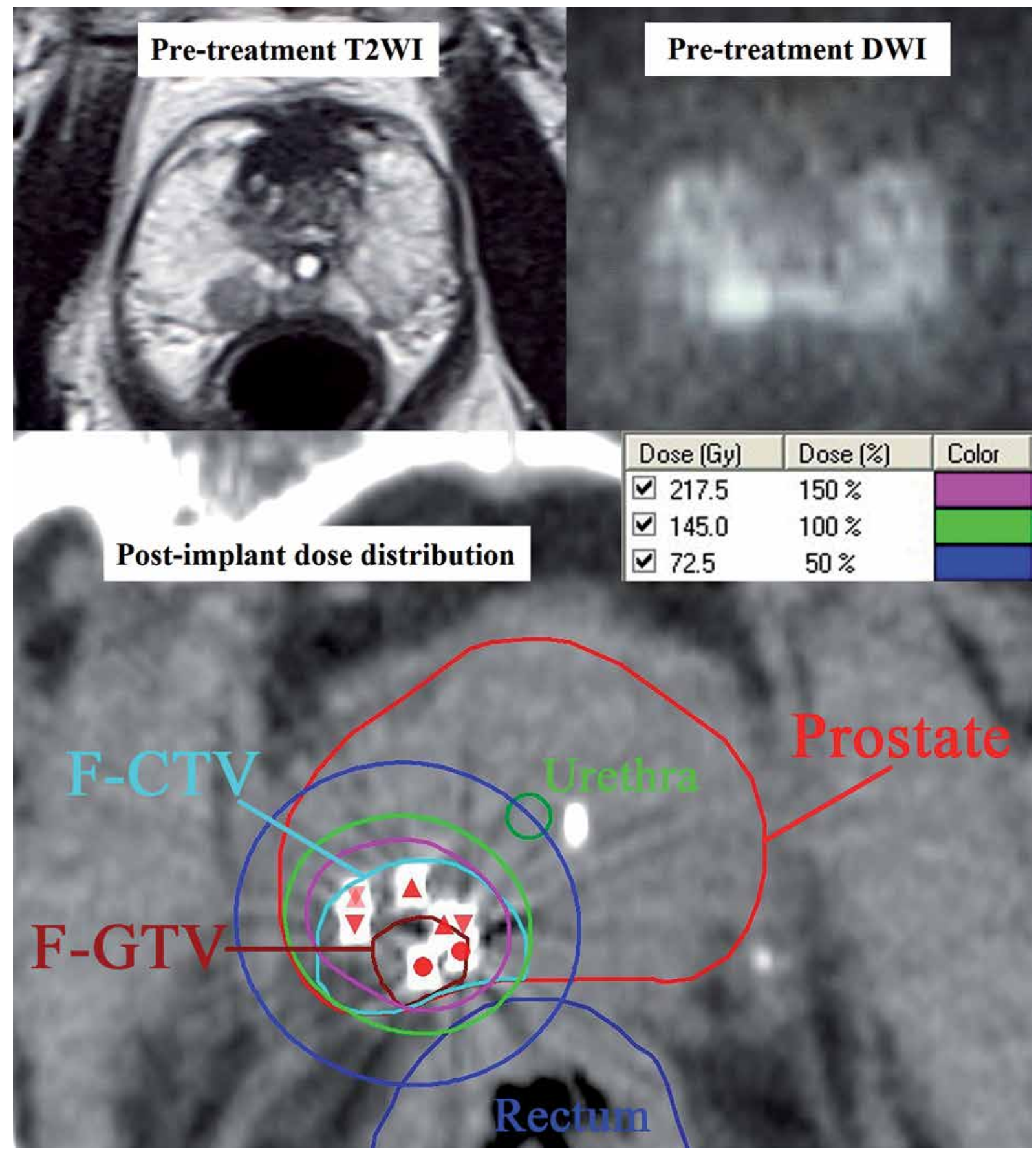

Fig. 1. Abnormality on pre-treatment T2-weighted and diffusion-weighted magnetic resonance images (T2WI and DWI, respectively), and a post-implant dose distribution on axial computed tomography in a representative patient. On the post-implant axial computed tomography image, the focal clinical target volume (F-GTV, dark brown), focal planning target volume (F-CTV, light blue), prostate (red), urethra (green), and rectum (blue) are contoured. The dose distributions are shown in blue $(50 \%=$ $72.5 \mathrm{~Gy})$, light green $(100 \%=145 \mathrm{~Gy})$, and purple $(150 \%=217.5 \mathrm{~Gy})$. The F-GTV received a dose of approximately $150 \%$, and the F-GTV plus a 5-mm margin (F-CTV) received a dose of approximately $100 \%$. Reductions in the prostate dose are apparent DWI - diffusion-weighted images, T2WI - T2-weighted magnetic resonance images

image of post-implant dose distribution in a representative patient. Seven $(37 \%)$ of the 19 patients received neoadjuvant hormonal therapy for 2-4 months just before focal brachytherapy to minimize interference by the pubic bone; no patient received adjuvant hormonal therapy. The median follow-up time was 31 (range, 12-67) months.

\section{Evaluation of pre- and post-implant dosimetric parameters}

Pre- and post-implant dosimetric parameters are described in Table 2. Reductions in the prostate dose were minimal. The mean F-GTV $\mathrm{D}_{90 \%}$ in post-implant dosime- 
Table 2. The estimated prostate volumes and dose-volume histograms in intraoperative planning and postimplant dosimetry

\begin{tabular}{|c|c|c|c|c|c|c|}
\hline & \multicolumn{2}{|c|}{ Intraoperative planning dosimetry } & \multicolumn{2}{|c|}{ Post-implant dosimetry } & \multirow{2}{*}{$\begin{array}{c}\text { Mean } \\
\text { difference }\end{array}$} & \multirow[t]{2}{*}{$P$-value } \\
\hline & Mean & SD & Mean & SD & & \\
\hline \multicolumn{7}{|l|}{ Prostate } \\
\hline Volume (ml) & 28.1 & 13.1 & 35.6 & 13.7 & -7.5 & 0.091 \\
\hline Prostate $\mathrm{D}_{50 \%}(\mathrm{~Gy})$ & 121.7 & 37.8 & 91.9 & 32.5 & 29.8 & 0.013 \\
\hline Prostate $\mathrm{D}_{90 \%}(\mathrm{~Gy})$ & 38.4 & 22.4 & 30.8 & 18.5 & 7.6 & 0.26 \\
\hline Prostate $\mathrm{V}_{100 \%}(\%)$ & 45.2 & 11.9 & 34.6 & 10.9 & 10.6 & 0.007 \\
\hline \multicolumn{7}{|l|}{ F-GTV } \\
\hline Volume (ml) & 2.9 & 2.2 & 2.8 & 2.7 & 0.1 & 0.87 \\
\hline F-GTV D $90 \%(G y)$ & 253.2 & 57.7 & 222 & 90.5 & 31.2 & 0.21 \\
\hline F-GTV D $100 \%$ (Gy) & 179.5 & 45 & 153 & 58.2 & 26.5 & 0.13 \\
\hline \multicolumn{7}{|l|}{ F-CTV } \\
\hline Volume (ml) & 6.9 & 3.5 & 8.2 & 4.5 & -1.3 & 0.34 \\
\hline F-CTV D $90 \%$ (Gy) & 210.4 & 39.4 & 163 & 54 & 47.4 & 0.004 \\
\hline \multicolumn{7}{|l|}{ Rectum } \\
\hline $\mathrm{RD}_{2 \mathrm{Cc}}(\mathrm{Gy})$ & 57.9 & 27 & 58 & 21.3 & -0.1 & 1 \\
\hline \multicolumn{7}{|l|}{ Urethra } \\
\hline $\mathrm{UD}_{10 \%}(\mathrm{~Gy})$ & 167.6 & 30.3 & 148.8 & 35.6 & 18.8 & 0.089 \\
\hline $\mathrm{UD}_{30 \%}(\mathrm{~Gy})$ & 147.2 & 29.3 & 125.9 & 31 & 21.3 & 0.036 \\
\hline
\end{tabular}

Prostate $D_{50 \%}$ and $D_{90 \%}$ - minimum doses delivered to $50 \%$ and $90 \%$ of the entire prostate, respectively, prostate $V_{100 \%}$ - percentage of the entire prostate covered by $100 \%$ of prescription dose, F-CTV $D_{90 \%}$ - minimum dose delivered to $90 \%$ of the F-CTV, F-GTV $D_{90 \%}$ and $D_{100 \%}$ - minimum doses delivered to $90 \%$ and $100 \%$ of the F-GTV, respectively, $R D_{2 c c}$ - the minimum dose received by maximum irradiated $2 \mathrm{cc}$ of the rectum, $U D_{10 \%}$ and $U D_{30 \%}-$ minimum doses received by $10 \%$ and $30 \%$ of the urethral volume, respectively

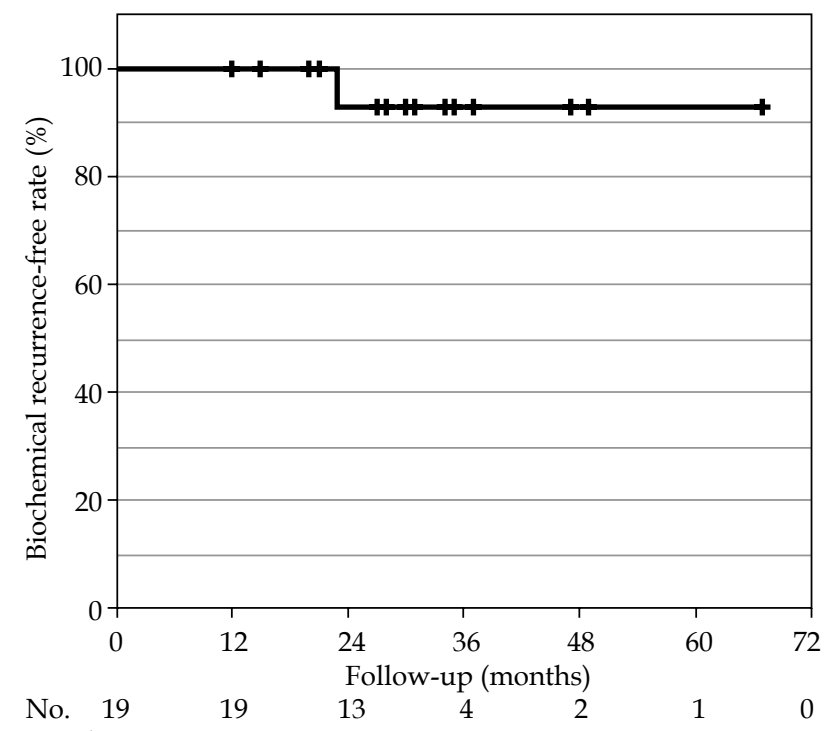
at risk

Fig. 2. Biochemical recurrence-free rate after focal permanent prostate brachytherapy

try was 222 (range, 147-559) Gy. The $\mathrm{UD}_{10 \%}, \mathrm{UD}_{30 \%}$, and $\mathrm{RD}_{2 \mathrm{cc}}$ in post-implant dosimetry were far below the ESTRO/EAU/EORTC recommendations [10] for wholegland prostate brachytherapy.

\section{Biochemical outcomes and disease control on MRI}

The 2-year BCR-free rate, determined by the Kaplan-Meier method was $92.9 \%$ (95\% confidence interval [CI]: 79.4-100\%; Figure 2). BCR occurred in one patient after 23 months (PSA level at 23 months: $3.96 \mathrm{ng} / \mathrm{ml}$; nadir: $1.62 \mathrm{ng} / \mathrm{ml}$ ). To evaluate the significant cancer control accordingly, 14 (74\%) of the 19 patients, excluding 5 patients with a short follow-up duration, underwent mpMRI. In 13 of these 14 patients, no tumor focus within the prostate was found; in the remaining patient, the patient with the increased PSA level, a new tumor focus in the seminal vesicle was found. This patient denied rebiopsy and requested hormonal therapy (PSA level at the last follow-up at 48 months, $0.54 \mathrm{ng} / \mathrm{ml}$ ). No patient died after focal brachytherapy.

\section{Toxicity}

Table 3 summarizes GI and GU toxicities. No patients had grade 1 or higher GI toxicities. The most frequent GU toxicity was grade 1 urinary frequency, which was often present before brachytherapy due to benign prostatic hyperplasia (BPH). In three patients $(16 \%)$, increased urinary frequency (grade 2) caused by $\mathrm{BPH}$, that was managed with the aid of a selective $\alpha 1$ adrenergic receptor antagonist, was present before brachytherapy and persisted to the last follow-up. These three patients experienced no treatment-related 
Table 3. Frequencies of genitourinary (GU) and gastrointestinal (GI) toxicities

Pre-treatment 12 months post-treatment 24 months post-treatment 36 months post-treatment

\begin{tabular}{lllll}
\hline No. of patients & 19 & 19 & 14 & 5 \\
\hline GU toxicity & 3 & 3 & 2 & 0 \\
\hline Grade 2 & 0 & 0 & 0 & 0 \\
\hline Grade 3 & & & 0 & 0 \\
\hline GI toxicity & 0 & 0 & 0 & 0
\end{tabular}

GU toxicity. Two patients suffered from temporary grade 2 urinary frequency caused by the brachytherapy (acute grade 2 GU toxicity). None of the remaining patients experienced grade 2 urinary frequency. No grade 2 or higher urinary incontinence or hematuria were observed. No patient experienced grade 3 or higher GU toxicities. Excluding the 15 patients with severe ED who did not request medication prior to focal brachytherapy, the remaining 4 patients did not develop ED as a result of brachytherapy.

\section{Discussion}

We performed focal LDR brachytherapy for MRIbased target with a margin, using MRI-TRUS fusion. The 2-year BCR-free rate, determined by the Kaplan-Meier method was $92.9 \%$. Our results demonstrate that LDR brachytherapy using an appropriate margin can be adaptable to focal therapy, as in a multicenter study of focal high-intensity focused ultrasound therapy [8]. That study reported failure-free survival rate, defined as freedom from local salvage therapy (surgery or radiotherapy), systemic therapy, metastases, and prostate cancer-specific death, of $92 \%$ at 3 years. In our study, the mean F-CTV $\mathrm{D}_{90 \%}$ in post-implant evaluation was significantly lower than that in intraoperative planning (mean difference, $47.4 \mathrm{~Gy}, p=0.004$ ). It appears difficult with focal brachytherapy using LDR sources to deliver doses to small targets due to source motion, such as migration. However, we demonstrated reasonable dose coverage (mean F-GTV $\mathrm{D}_{90 \%}, 222 \mathrm{~Gy}$; mean prostate $\mathrm{V}_{100 \%}, 35 \%$ ) while sparing the rectum and urethra (Table 2).

Table 4. Clinical results of focal permanent prostate brachytherapy with a safety margin

\begin{tabular}{|c|c|c|c|c|c|c|c|c|c|c|}
\hline Study & Year & $\begin{array}{c}\text { No. of } \\
\text { patients }\end{array}$ & $\begin{array}{c}\text { Risk } \\
\text { stratifi- } \\
\text { cation }\end{array}$ & $\begin{array}{l}\text { Clinical target } \\
\text { volume }\end{array}$ & $\begin{array}{l}\text { LDR BT } \\
\text { dose } \\
\text { (Gy) } \\
\text { for I }\end{array}$ & $\begin{array}{l}\text { Post-implant } \\
\text { dosimetry for } \\
\text { target volume } \\
\text { (mean) }\end{array}$ & $\begin{array}{l}\text { Cumulative } \\
\text { incidence } \\
\text { of } \mathrm{BCR}(\%)\end{array}$ & $\begin{array}{l}\text { Median } \\
\text { follow-up } \\
\text { (months) }\end{array}$ & $\begin{array}{l}\text { Grade } \\
+ \text { GU }\end{array}$ & $\begin{array}{l}\text { Grade } 3 \\
+\mathrm{Gl}\end{array}$ \\
\hline \multirow{3}{*}{$\begin{array}{l}\text { Cosset } \\
\text { et al. [19] }\end{array}$} & \multirow[t]{3}{*}{2013} & 21 & & \multirow{3}{*}{$\begin{array}{l}\text { MRI-based vol- } \\
\text { ume plus safety } \\
\text { margin }\end{array}$} & \multirow[t]{3}{*}{145} & \multirow{3}{*}{$\begin{array}{c}183 \text { Gy } \\
\text { (MRI-based } \\
\text { volume } D_{90 \%} \text { ) }\end{array}$} & \multirow{3}{*}{$\begin{array}{l}0 \% \text { at } \\
1 \text { year }\end{array}$} & $<2$ years & $0 \%$ & $0 \%$ \\
\hline & & 19 & Low & & & & & & & \\
\hline & & 2 & $\begin{array}{l}\text { Inter- } \\
\text { mediate }\end{array}$ & & & & & & & \\
\hline \multirow{3}{*}{$\begin{array}{l}\text { Mahdavi } \\
\text { et al. [20] }\end{array}$} & \multirow[t]{3}{*}{2017} & 5 & & \multirow{3}{*}{$\begin{array}{l}\text { TTMB-based } \\
\text { cancer locations } \\
\text { plus } 5 \mathrm{~mm}\end{array}$} & \multirow[t]{3}{*}{144} & \multirow{3}{*}{$\begin{array}{c}90.4 \% \\
\text { (pre-treatment } \\
\text { image-based } \\
\text { volume } \mathrm{V}_{100 \%} \text { ) }\end{array}$} & \multirow{3}{*}{$\begin{array}{l}0 \% \text { at } \\
1 \text { year }\end{array}$} & 19 & $0 \%$ & $0 \%$ \\
\hline & & 3 & Low & & & & & & & \\
\hline & & 2 & $\begin{array}{l}\text { Inter- } \\
\text { mediate }\end{array}$ & & & & & & & \\
\hline \multirow{3}{*}{$\begin{array}{l}\text { Graff et al. } \\
\text { [21] }\end{array}$} & \multirow[t]{3}{*}{2018} & 17 & & \multirow{3}{*}{$\begin{array}{l}\text { MRI-based vol- } \\
\text { ume plus } 2 \mathrm{~mm}\end{array}$} & \multirow[t]{3}{*}{160} & \multirow[t]{3}{*}{-} & \multirow{3}{*}{$\begin{array}{l}0 \% \text { at } \\
1 \text { year }\end{array}$} & $<2$ years & $0 \%$ & $0 \%$ \\
\hline & & 13 & Low & & & & & & & \\
\hline & & 4 & $\begin{array}{l}\text { Inter- } \\
\text { mediate }\end{array}$ & & & & & & & \\
\hline \multirow{3}{*}{$\begin{array}{l}\text { Present } \\
\text { study }\end{array}$} & & 19 & & \multirow{3}{*}{$\begin{array}{l}\text { MRI-based vol- } \\
\text { ume plus } 5 \mathrm{~mm}\end{array}$} & \multirow[t]{3}{*}{145} & \multirow{3}{*}{$\begin{array}{l}222 \text { (MRI-based } \\
\text { volume } \mathrm{D}_{90 \%} \text { ) }\end{array}$} & \multirow{3}{*}{$\begin{array}{l}0 \% \text { at } \\
1 \text { year, } \\
7.1 \% \text { at } \\
2 \text { years }\end{array}$} & 31 & $0 \%$ & $0 \%$ \\
\hline & & 8 & Low & & & & & & & \\
\hline & & 11 & $\begin{array}{c}\text { Inter- } \\
\text { mediate }\end{array}$ & & & & & & & \\
\hline
\end{tabular}

$B C R$ - biochemical recurrence, $B T$ - brachytherapy, $D_{90 \%}$ - minimum doses received by $90 \%$ of the volume, respectively, GI - gastrointestinal, GU - genitourinary, $I$ - iodine, $L D R$ - low-dose-rate, MRI - magnetic resonance imaging, TTMB - transperineal template mapping biopsy, $V_{100 \%}$ - percentage of the volume receiving $100 \%$ of the prescribed dose 
Only a few reports, which included small patient numbers have evaluated the effectiveness of focal implantation $[19,20,21]$ (Table 4), of which two showed the feasibility of focal LDR prostate brachytherapy, with promising short-term outcomes $[19,20]$. Compared with other studies, we assessed the cumulative incidence of BCR over a longer follow-up period (median follow-up, 31 months). Cosset et al. [19] administered focal LDR prostate brachytherapy delivering $145 \mathrm{~Gy}$ at both positive biopsy sites and MRI with a safety margin to 21 patients. They reported that the mean initial PSA level decreased from 6.9 to $3.2 \mathrm{ng} / \mathrm{ml}$ at 6 months and, in 11 of the 21 patients evaluated at 1 year of follow-up, it had decreased further to $2.6 \mathrm{ng} / \mathrm{ml}$, with no GU or GI toxicity. Mahdavi et al. [20] used focal LDR prostate brachytherapy delivering a prescription dose of 144 Gy to TTMB-detected cancer sites, plus a $5-\mathrm{mm}$ margin, in five patients. In that study, no GU and GI toxicities were reported; although, the mean post-implant dose to the target in that five patients was not reported. According to our calculation, the $\mathrm{V}_{100 \%}$ for TRUS- and MRI-based volume would have been $90.4 \%$ in that study. Graff et al. [21] designed ultra-focal LDR brachytherapy delivering $160 \mathrm{~Gy}$ to MRI-determined gross tumor volume, plus a 2-mm margin, in 17 patients. They assessed the feasibility of delivering $\geq 95 \%$ of prescribed dose ( $\geq 152$ Gy) to $100 \%$ of MRI-determined gross tumor volume in ultra-focal LDR brachytherapy.

Determining the optimal margin setting is necessary for focal LDR brachytherapy planning; we used a margin of $5 \mathrm{~mm}$ to compensate for uncertainties in image registration and treatment delivery. Smaller margins of uncertainty increase the risk of PSA failure, whereas larger margins lead to whole-gland rather than focal brachytherapy. The mean post-implant prostate $\mathrm{V}_{100 \%}$ in our study was 35\% (Table 2); therefore, our brachytherapy method did result in prostate dose reductions. In the study by Mahdavi et al. [20] on focal LDR brachytherapy, a 5-mm margin was added to targets derived from cancer sites by TTMB. Graff et al. [21] designed focal LDR brachytherapy using MRI-determined gross tumor volume plus a 2-mm margin. Appropriate margin determination at each institution will be required for effective focal brachytherapy.

In post-implant dosimetric evaluation of the index tumor, the delineation of gross visible area can be insufficient when using T2WI. There are also post-implant registration errors for $\mathrm{CT}$ and T2WI. Groenendaal et al. [12] reported an application of a 5-mm margin to MRI-delineated tumors to cover approximately $85-100 \%$ of the tumor. Therefore, we evaluated not only the post-implant F-GTV, but also the post-implant F-CTV, plus a 5-mm margin on MRI-based tumor delineation. In post-implant dosimetric analysis of focal LDR brachytherapy, it may be important to evaluate MRI-determined volume with an appropriate margin.

Focal LDR brachytherapy may increase the risk of PSA failure due to the difficulty with dose delivery for small volumes, compared with conventional whole-gland prostate brachytherapy. The total number of sources is smaller in focal LDR brachytherapy than in whole-gland brachytherapy, and the influence of seed motion on each source can be greater.
Hemi-gland brachytherapy is an option for focal brachytherapy. It has been reported that the treatmentrelated toxicities and biochemical outcomes of hemigland LDR brachytherapy for unilateral localized prostate cancer are broadly similar to those of whole-gland brachytherapy. Although, post-implant dose to the urethra and rectum was significantly lower in hemi-gland brachytherapy, compared with whole-gland brachytherapy [22]. It is difficult to conclude which focal LDR brachytherapy (hemi-gland vs. MRI-based target) is superior at this time.

In the case of PSA failure, focal partial salvage prostate brachytherapy could be a recommended treatment option $[23,24]$. However, in our study, the one case of PSA failure had suspicious seminal vesicle recurrence according to mpMRI, and therefore was administered hormonal therapy at the patient's request.

Focal brachytherapy may serve as a minimally invasive therapeutic option, particularly for patients with symptoms of bladder outlet obstruction. The NCCN guidelines [25] state that patients with such symptoms exhibit an increased risk of side effects after wholegland prostate brachytherapy. The three patients in our study who were on alpha-blockers (to treat $\mathrm{BPH}$ ) prior to brachytherapy, experienced no treatment-related genitourinary toxicity. However, there is a need to evaluate larger number of patients with symptoms of bladder outlet obstruction in a future multi-institutional study.

A limitation of this study was that no patient received prostate biopsy, such as 5-mm TTMB, after focal brachytherapy due to good PSA control. In this study, follow-up mpMRI was performed in 14 of the 19 patients (74\%); the other 5 patients were followed for a short time, with no findings of local recurrence. However, it is difficult to diagnose local recurrence after radiation, since brachytherapy causes glandular atrophy and fibrosis, which reduces the signal intensity on T2WI, and artifacts caused by the sources can affect diffusion-weighted imaging [26].

Our patient numbers were small, and the follow-up interval was short; thus, it is difficult to draw robust conclusions. A randomized clinical study is required to evaluate the real efficacy and feasibility of focal LDR therapy for low- and intermediate-risk prostate cancer.

\section{Conclusions}

We report a low BCR rate after focal LDR brachytherapy for low- and intermediate-risk prostate cancer. The LDR approach may serve as a useful, minimally invasive focal therapeutic option. Longer term follow-up is needed.

\section{Disclosure}

The authors report no conflict of interest.

\section{References}

1. Stamey TA, Caldwell M, McNeal JE et al. The prostate specific antigen era in the United States is over for prostate cancer: what happened in the last 20 years? J Urol 2004; 172: 12971301. 
2. Okamoto K, Okuyama K, Kohno N et al. Clinical outcomes of low-dose-rate brachytherapy based radiotherapy for intermediate risk prostate cancer. J Contemp Brachytherapy 2020; 12: 6-11.

3. Wise AM, Stamey TA, McNeal JE et al. Morphologic and clinical significance of multifocal prostate cancers in radical prostatectomy specimens. Urology 2002; 60: 264-269.

4. Ahmed HU. The index lesion and the origin of prostate cancer. N Engl J Med 2009; 361: 1704-1706.

5. Lindner U, Trachtenberg J, Lawrentschuk N. Focal therapy in prostate cancer: modalities, findings and future considerations. Nat Rev Urol 2010; 7: 562-571.

6. Langley S, Ahmed HU, Al-Qaisieh B et al. Report of a consensus meeting on focal low dose rate brachytherapy for prostate cancer. BJU Int 2012; 109 Suppl: 7-16.

7. Haworth A, Williams S. Focal therapy for prostate cancer: the technical challenges. J Contemp Brachytherapy 2017; 9: 383-389.

8. Guillaumier S, Peters M, Arya M et al. A multicentre study of 5-year outcomes following focal therapy in treating clinically significant nonmetastatic prostate cancer. Eur Urol 2018; 74: 422-429.

9. Ferro A, Bae HJ, Yenokyan G et al. Reductions in prostatic doses are associated with less acute morbidity in patients undergoing Pd-103 brachytherapy: Substantiation of the rationale for focal therapy. Brachytherapy 2018; 17: 313-318.

10. Salembier C, Lavagnini P, Nickers P et al. Tumour and target volumes in permanent prostate brachytherapy: a supplement to the ESTRO/EAU/EORTC recommendations on prostate brachytherapy. Radiother Oncol 2007; 83: 3-10.

11. Kunogi H, Hojo H, Wakumoto $\mathrm{Y}$ et al. A new two-step accurate CT-MRI fusion technique for post-implant prostate cancer. I Contemp Brachytherapy 2015; 7: 117-121.

12. Groenendaal G, Moman MR, Korporaal JG et al. Validation of functional imaging with pathology for tumor delineation in the prostate. Radiother Oncol 2010; 94: 145-150.

13. Muto S, Yoshii T, Saito K et al. Focal therapy with high-intensity-focused ultrasound in the treatment of localized prostate cancer. Jpn J Clin Oncol 2008; 38: 192-199.

14. Kongnyuy M, Islam S, Mbah AK et al. PSA kinetics following primary focal cryotherapy (hemiablation) in organ-confined prostate cancer patients. World J Urol 2018; 36: 209-213.

15. NCI. CTCAE. Available from: URL:http://evs.nci.nih.gov/ ftp1/CTCAE/ About.html (accessed 17 May, 2010).

16. Schoentgen N, Marolleau J, Delage F et al. Prospective four years of evaluation of erectile function after low-dose-rate prostate brachytherapy using baseline IIEF-5 > 16. J Contemp Brachytherapy 2019; 11: 195-200.

17. Brun T, Bachaud JM, Graff-Cailleaud P et al. New approach of ultra-focal brachytherapy for low- and intermediate-risk prostate cancer with custom-linked I-125 seeds: A feasibility study of optimal dose coverage. Brachytherapy 2018; 17: 544-555.

18. Warrell GR, Xing Y, Podder TK et al. Reduction of seed motion using a bio-absorbable polymer coating during permanent prostate brachytherapy using a mick applicator technique. J Appl Clin Med Phys 2018; 19: 44-51.

19. Cosset JM, Cathelineau X, Wakil G et al. Focal brachytherapy for selected low-risk prostate cancers: a pilot study. Brachytherapy 2013; 12: 331-337.

20. Mahdavi SS, Spadinger IT, Salcudean SE et al. Focal application of low-dose-rate brachytherapy for prostate cancer: a pilot study. J Contemp Brachytherapy 2017; 9: 197-208.

21. Graff P, Portalez D, Lusque A et al. IDEAL 2a Phase II study of ultrafocal brachytherapy for low- and intermediate-risk prostate cancer. Int J Radiat Oncol Biol Phys 2018; 102: 903-911.

22. Langley S, Uribe J, Uribe-Lewis $S$ et al. Hemi-ablative lowdose-rate prostate brachytherapy for unilateral localised prostate cancer. BJU Int 2020; 125: 383-390.
23. Hsu CC, Hsu H, Pickett B et al. Feasibility of MR imaging/ MR spectroscopy-planned focal partial salvage permanent prostate implant (PPI) for localized recurrence after initial PPI for prostate cancer. Int J Radiat Oncol Biol Phys 2013; 85: 370-377.

24. Kunogi H, Wakumoto $\mathrm{Y}$, Yamaguchi N et al. Focal partial salvage low-dose-rate brachytherapy for local recurrent prostate cancer after permanent prostate brachytherapy with a review of the literature. J Contemp Brachytherapy 2016; 8: 165-172.

25. National Comprehensive Cancer Network. Available at: https://www.nccn.org/professionals/physician_gls/pdf/ prostate.pdf.

26. Venkatesan AM, Stafford RJ, Duran C et al. Prostate magnetic resonance imaging for brachytherapists: Diagnosis, imaging pitfalls, and post-therapy assessment. Brachytherapy 2017; 16: 688-697. 